\title{
Neuroprotective Effects of Pharmacological Hypothermia on Glucose Metabolism in Ischemic Rats
}

\author{
Longfei Guan \\ Capital Medical University \\ Hangil Lee \\ Wayne State University School of Medicine \\ Xiaokun Geng \\ Capital Medical University \\ Fengwu Li \\ Capital Medical University \\ Jiamei Shen \\ Capital Medical University \\ Yu Ji \\ Capital Medical University \\ Changya Peng \\ Wayne State University School of Medicine \\ Huishan Du \\ Capital Medical University \\ Yuchuan Ding ( $\nabla$ yding@med.wayne.edu ) \\ Wayne State University School of Medicine https://orcid.org/0000-0001-5358-1660
}

\section{Research Article}

Keywords: Stroke, Ischemia/reperfusion injury, Combination therapy of chlorpromazine and promethazine (C+P) with dihydrocapsaicin (DHC), Glycolysis, Gluconeogenesis

Posted Date: November 3rd, 2021

DOI: https://doi.org/10.21203/rs.3.rs-1030512/v1

License: (c) (i) This work is licensed under a Creative Commons Attribution 4.0 International License. Read Full License 


\section{Abstract}

Stroke is a leading threat to human life. Metabolic dysfunction of glucose may play a key role in stroke pathophysiology. Pharmacological hypothermia $(\mathrm{PH})$ is a potential neuroprotective strategy for stroke in which the temperature can be decreased safely. The present study determined whether neuroprotective $\mathrm{PH}$ with chlorpromazine and promethazine (C+P) plus dihydrocapsaicin (DHC) improved glucose metabolism in acute ischemic stroke. A total of 208 adult male SpragueDawley rats were randomly divided into the following groups: sham, stroke, and stroke with various treatments including C+P, DHC, C+P+DHC, phloretin (glucose transporter (GLUT)-1 inhibitor), cytochalasin B (GLUT-3 inhibitor), TZD (thiazolidinedione, phosphoenolpyruvate carboxykinase (PCK) inhibitor) and apocynin (nicotinamide adenine dinucleotide phosphate oxidase (NOX) inhibitor). Stroke was induced by middle cerebral artery occlusion (MCAO) for $2 \mathrm{~h}$ followed by 6 or $24 \mathrm{~h}$ of reperfusion. Rectal temperature was monitored before, during, and after $\mathrm{PH}$. Infarct volume and neurological deficits were measured to assess the neuroprotective effects. Reactive oxygen species (ROS), NOX activity, lactate, apoptotic cell death, glucose, and ATP levels were measured. Protein expressions of GLUT-1, GLUT-3, phosphofructokinase (PFK), lactate dehydrogenase (LDH), PCK1, PCK2, and NOX subunit gp91 were measured with Western blotting. PH with combination of C+P and DHC induced a faster, longer, and deeper hypothermia as compared to each alone. PH significantly improved every measured outcome as compared to stroke and monotherapy. $\mathrm{PH}$ reduced brain infarction, neurological deficits, protein levels of glycolytic enzymes (GLUT-1, GLUT-3, PFK and LDH), gluconeogenic enzymes (PCK1 and PCK2), NOX activity and its subunit gp91, ROS, apoptotic cell death, glucose, and lactate, while raising ATP levels. In conclusion, stroke impaired glucose metabolism by enhancing hyperglycolysis and gluconeogenesis, which led to ischemic injury, all of which were reversed by $\mathrm{PH}$ induced by a combination of $\mathrm{C}+\mathrm{P}$ and $\mathrm{DHC}$.

\section{Introduction}

Stroke is the second-most frequent cause of death and a leading cause of disability worldwide, with an increasing incidence in developing countries [1]. Ischemic stroke caused by arterial occlusion is responsible for the majority of strokes [2]. Recanalization and reperfusion are the mainstays of acute stroke treatment and can reduce infarct sizes and reverse neurologic deficits [3]. Current clinical management focuses on rapid reperfusion with intravenous thrombolysis and endovascular thrombectomy, which benefit only a small proportion of stroke patients due to the narrow therapeutic window and contraindications $[4,5]$. Despite increasing rates of recanalization, $50 \%$ of the patients still end up with new disabilities after ischemic events [6]. Therefore, identification of new therapeutic modalities is critical to improve stroke outcomes. As the STAIR conferences recommended, there are ample opportunities to study and develop new neuroprotective agents, as well as repurposing known agents, as adjunct treatments to reperfusion therapy in the era of highly effective reperfusion $[7,8]$.

Therapeutic hypothermia $(\mathrm{TH})$ has been recognized as one of the most effective potential treatments of stroke $[9,10]$. $\mathrm{TH}$ decreases metabolic activity, reactive oxygen species (ROS), and inflammation [11], thus preventing the expansion of irreversible injury and saving reversible ischemic penumbra. However, delayed induction of cerebral hypothermia, increased incidence of pneumonia, and intensive labor limit its application in the clinical setting [12]. Pharmacological hypothermia (PH) is an alternative to physically induced hypothermia, in which the temperature is carefully decreased by drugs without the risks and labor of traditional hypothermia [13]. Dihydrocapsaicin (DHC) and two phenothiazines, chlorpromazine and promethazine $(\mathrm{C}+\mathrm{P})$, are a combination that has proven to be efficacious in animal studies [14]. DHC is a capsaicin analog that confers hypothermia by decreasing metabolism [15]. C+P are neuroleptic drugs that induce an "artificial hibernation"-like state [16].

To date, it has been observed that increased ROS levels, glycolysis, and lactic acidosis are responsible for brain tissue injury and death [17]. However, therapies that specifically target these domains did not ameliorate ischemic damage [18]. One of the candidates to the missing link may be gluconeogenesis. Recent studies found that the brain also undergoes gluconeogenesis, which is usually overshadowed by the organs we typically associate with generating glucose de novo such as the liver, intestines, kidneys, and muscle [19]. When the brain undergoes acute ischemic stroke (AIS), gluconeogenesis in the brain tissue is interrupted due to shortage of ATP, leading to accumulation of undesirable side products. These side products, which include lactic acid and ROS, contribute to cellular injury and death [20]. The lack of consideration for gluconeogenesis may

Page $2 / 21$ 
have caused the failure of previous therapies, which targeted downstream side products rather than their source.

Hyperglycolysis may be yet another contributor to brain injury that deserves greater attention. It has been observed to correlate with greater brain injury [21], possibly through mitochondrial oxidative phosphorylation decoupling [22]. Specifically in AIS, hyperglycolysis contributes to the energy crisis that ultimately leads to brain damage [23]. More convincingly, many treatment modalities have ameliorated AIS damage by decreasing hyperglycolysis [24, 25], one of which includes C+P [26].

Although it has been shown that $\mathrm{C}+\mathrm{P}+\mathrm{DHC}$ offers neuroprotection, there is much that remains to be studied. While it is clear that the combination is efficacious, the underlying molecular mechanism of efficacy is yet to be elucidated. More evidence is needed to show that the combination better enhances neuroprotection as compared to each formulary alone. Whether glucose metabolism plays a role in amelioration of AIS by $\mathrm{C}+\mathrm{P}+\mathrm{DHC}$ also remains to be explored. Finally, although $\mathrm{C}+\mathrm{P}+\mathrm{DHC}$ has been described to ameliorate brain damage, its dependence or independence to hypothermia requires further validation [20,26].

The present study determined whether $\mathrm{PH}$ with $\mathrm{C}+\mathrm{P}$ and $\mathrm{DHC}$ led to neuroprotection by improving glucose metabolism in acute ischemic stroke. More specifically, we hypothesized that the induction of hyperglycolysis and gluconeogenesis, and thus their contribution to oxidative injury and acidosis in ischemia/reperfusion injury, can be reduced by $\mathrm{PH}$. The conclusions we draw may unlock new treatment modalities that better prevent brain tissue death in stroke.

\section{Materials And Methods}

\section{Subject}

All experimental design and procedures were approved by the Institutional Animal Investigation Committee of Capital Medical University in accordance with the National Institutes of Health (USA) guidelines for care and use of laboratory animals. From 226 adult Sprague-Dawley rats (280-300g, from Vital River Laboratory Animal Technology Co Ltd, China) originally enrolled to the study, 208 could be used for experiments; 3 died after surgery, and 15 excluded due to unsuccessful surgery. Animals were randomly divided into the following groups: 1$)$ sham-operated group without middle cerebral artery occlusion $(\mathrm{MCAO})(\mathrm{n}=8 \times 2)$ and 2) $2 \mathrm{~h} \mathrm{MCAO}$ group followed by $6 \mathrm{~h}(\mathrm{n}=8 \times 8), 24 \mathrm{~h}(n=8 \times 8)$, or $48 \mathrm{~h}(n=8 \times 8)$ of reperfusion. The MCAO group were further randomly divided into 8 subgroups with different treatments: 1) vehicle with saline, 2) C+P; 3) DHC; 4) combination of C+P and DHC; 5) phloretin (glucose transporter (GLUT)-1 inhibitor); 6) cytochalasin B (GLUT-3 inhibitor); 7) TZD (thiazolidinedione, PCK inhibitor); and 8) apocynin (nicotinamide adenine dinucleotide phosphate oxidase (NOX) inhibitor). At $48 \mathrm{~h}$ of reperfusion the infarct volume in animals with MCAO was analyzed, and at 6 or $24 \mathrm{~h}$ of reperfusion the protein and biochemical measurements were analyzed. Animals were housed under a 12-hour light/dark cycle and were kept in the same animal care facility for the entire duration of the study. All efforts were made to minimize any suffering and to reduce the total number of animals used.

\section{Focal Cerebral Ischemia and Reperfusion}

This model has been described previously by us [27]. Briefly, rats were fasted $12 \mathrm{~h}$ before surgery and then subjected to two hours of MCAO (right side) using an intraluminal filament. Rats were anesthetized in a chamber with 1-3\% isoflurane in a mixture of $70 \%$ nitrous oxide and $30 \%$ oxygen. Then, they were transferred to a surgical table and anesthesia was maintained with a facemask using $1 \%$ isoflurane delivered from a calibrated precision vaporizer. Poly-L-lysine-coated intraluminal nylon (4.0) sutures were used to occlude the MCA, which yielded consistent infarcts and significantly reduced inter-animal variability. Two hours after occlusion, reperfusion was established by withdrawal of the filament under anesthesia. Buprenorphine $0.01 \mathrm{mg} / \mathrm{kg}$ s.c. was used 30 minutes before the incision and after surgery every 8-12 $\mathrm{h}$ as needed for $24 \mathrm{~h}$ postop for analgesia.

\section{Pharmacological Hypothermia with C+P and DHC, and Inhibitor Administration}


In ischemia models with $2 \mathrm{~h}$ MCAO with reperfusion, a 1:1 ratio of chlorpromazine and promethazine (C+P) at $4 \mathrm{mg} / \mathrm{kg}$ in $3 \mathrm{ml}$ of saline, dihydrocapsaicin (DHC) at doses of $0.5 \mathrm{mg} / \mathrm{kg}$, or a combination of C+P and DHC was injected intraperitoneally at the onset of reperfusion after $2 \mathrm{~h}$ ischemia as previously described by us [14]. In order to maintain and enhance the efficacy of the drugs, a second injection of C+P with $1 / 3$ of the original dose was delivered in $2 \mathrm{~h}$. Alternatively, $100 \mathrm{mg} / \mathrm{kg}$ of phloretin (GLUT-1 inhibitor), $0.5 \mathrm{mg} / \mathrm{kg}$ of cytochalasin B (GLUT-3 inhibitor), $2.5 \mathrm{mg} / \mathrm{kg}$ TZD (PCK inhibitor), or 2.5 $\mathrm{mg} / \mathrm{kg}$ apocynin (NOX inhibitor) were injected $2 \mathrm{~h}$ after the onset of ischemia. Rectal temperature (body temperature) was monitored before surgery and after hypothermia until it returned to the baseline.

\section{Infarct Volume}

Infarct volumes were evaluated at $48 \mathrm{~h}$ of reperfusion in all rats. The brains were resected from ischemic rats. Then, the regions supplied by MCA were cut into $2 \mathrm{~mm}$ thick slices with brain matrix and treated with 2, 3, 5-triphenyltetrazolium chloride (TTC, Sigma, USA) for staining at $37^{\circ} \mathrm{C}$. An indirect method for calculating infarct volume was used to minimize error caused by edema. We also measured and compared infarct size of the cortex and striatum at three different levels from anterior +1.00 $\mathrm{mm}$ to posterior $-4.8 \mathrm{~mm}$ to the bregma of the brain [28].

\section{Neurological Deficits}

The severity of neurological deficits were evaluated using the modified scoring systems ( 5 and 12 scores) proposed by Longa et al. [29] and Belayev et al. [30] before surgery for baseline, after $2 \mathrm{~h}$ MCA occlusion (during MCA occlusion, just before reperfusion), and after $48 \mathrm{~h}$ reperfusion. Higher scores indicate more severe deficits in both scoring systems. The severity and consistency of brain damage in each group were important to this study. After MCA occlusion, the modified scoring system (five score) for neurological deficits was used to confirm brain injury. The MCA occlusions were considered unsuccessful and the rats excluded from the study if the score was 1 or below; approximately $10 \%$ of animals with MCA occlusion were discarded for this reason.

\section{Cerebral Glucose, Lactate, and ATP Production}

Glucose and lactate levels in the brain was detected using the Glucose and Lactate Assay Kits (BioVision) as previously described by us [31]. Right cerebral hemispheres, including the frontoparietal cortex and striatum supplied by MCA, were extracted and homogenized, then measured by a DTX-880 multimode detector at an absorbance wavelength of 570 or $450 \mathrm{~nm}$ respectively. ATP levels were determined by an ATP Colorimetric/Fluorometric Assay Kit (Biovision) according to the manufacturer's protocols as described previously by us [27]. Briefly, a $50 \mu$ l brain sample in ATP assay buffer and $50 \mu$ ATP reaction mix were added to the 96 plate wells and incubated for $\mathbf{3 0}$ min at room temperature while avoiding any exposure to light. Absorbance of $570 \mathrm{~nm}$ was then detected.

\section{ROS Production}

ROS was measured by assessing $\mathrm{H}_{2} \mathrm{O}_{2}$ with hydrogen peroxidase linked to a fluorescent compound as described previously by us [32]. Briefly, homogenized brain samples taken from the MCA supplied territory (cortex and striatum) were diluted to 10 $\mathrm{mg} / \mathrm{ml} . \mathrm{H}_{2} \mathrm{O}_{2}$ levels in brain homogenates were determined at $37^{\circ} \mathrm{C}$ on a DTX-880 Multimode Detector.

\section{NADPH Oxidase (NOX) Activity}

Brain samples of the MCA supplied regions were homogenized in PBS buffer ( $120 \mathrm{mM} \mathrm{NaCl}, 4.8 \mathrm{mM} \mathrm{KCl,} 1.2 \mathrm{mM} \mathrm{MgSO}_{4}, 2.2$

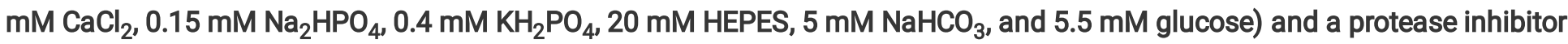


cocktail. An $80 \mu$ l homogenizing buffer supplemented with $6.25 \mu \mathrm{M}$ lucigenin mix and $20 \mu \mathrm{L}$ of homogenate were added to each well of the luminescence plate and incubated for 10 minutes at $37^{\circ} \mathrm{C}$. The reaction was initiated after adding NADPH $(100 \mu \mathrm{M})$, and luminescence was recorded with a DTX-880 multimode detector every $30 \mathrm{~s}$ for a total of 5 min [31].

\section{Cell Death}

The level of apoptotic cell death was measured using a commercial enzyme immunoassay kit determining cytoplasmic histone-associated DNA fragments (Roche Diagnostics), as described previously by us [16]. Absorbance of $405 \mathrm{~nm}$ was detected with a multimode detector (Beckman DTX-880).

\section{Protein Expression}

Western blot analysis was used to assess protein expression in the ischemic tissue, as described previously by us [33]. Briefly, proteins were extracted from rat brain isolates and loaded onto gels for electrophoresis. Then the proteins were transferred to a polyvinylidene fluoride membrane. Membranes were incubated with a primary antibody overnight at $4^{\circ} \mathrm{C}$. Primary antibodies included anti-PFK (1:1000, Santa Cruz), anti-GLUT-1 (1:1000, Abcam), anti-GLUT-3 (1:1000, Santa Cruz), anti-LDH (1:1000, Santa Cruz), anti-PCK1 (1:1000, Cell Signaling Technology), anti-PCK2 (1:1000, Cell Signaling Technology), anti-gp91 (1:1000, Abcam), and anti- $\beta$-actin (1:1000, Santa Cruz). Next, membranes were washed and re-incubated with a secondary antibody (goat anti-rabbit IgG, (Santa Cruz)) for $1 \mathrm{~h}$ at room temperature. Target protein expressions were visualized using an enhanced chemiluminescence kit (Millipore, Billerica, MA, USA). Western blot images were analyzed using an image analysis program (Image J 1.42, National Institutes of Health, USA) to quantify protein expression in terms of relative image density. The mean amount of protein expression in the control group was assigned a value of 1 to serve as reference.

\section{Statistical Analysis}

The statistical analyses were performed with Graphpad Prism V8.0.2 (Graphpad Software, San Diego, CA, USA). The D'Agostino-Pearson test was used to assess normal distribution. The differences among groups were calculated using a oneway ANOVA (after confirming normal distribution) or Kruskal-Wallis test with a significance level set at $p<0.05$. Post hoc comparison between groups used the least significant difference method. The data and values are all expressed as the mean \pm SD.

\section{Results}

\section{Physiological Parameters}

Physiological parameters were measured before surgery (Pre MCAO), after $2 \mathrm{~h} \mathrm{MCA}$ occlusion (Pre reperfusion), and after $2 \mathrm{~h}$ reperfusion. A catheter was inserted into the right femoral artery for continuous monitoring of mean arterial pressure (MAP) and periodic analyses of blood gases and $\mathrm{pH}[34,20]$. There were no significant differences in blood $\mathrm{pH}, \mathrm{pO}_{2}, \mathrm{pCO}_{2}$, or mean arterial pressure (MAP) between the groups (data are shown in the supplemental materials).

\section{Induction of Pharmacological Hypothermia}

In the absence of external heating, body temperature was maintained at $37.4^{\circ} \mathrm{C}$ in the stroke group without treatment, while other groups receiving different treatments $(\mathrm{C}+\mathrm{P}, \mathrm{DHC}$, and $\mathrm{C}+\mathrm{P}+\mathrm{DHC})$ were significantly reduced (Figure $1 \mathrm{~A})$. At reperfusion onset, $\mathrm{C}+\mathrm{P}$ or $\mathrm{DHC}$ reduced temperature to hypothermic levels (below $36^{\circ} \mathrm{C}$ ) from 20 min or $1 \mathrm{~h}$. Combination of C+P and DHC induced a faster (at $5 \mathrm{~min}$ ), longer (up to $6 \mathrm{~h}$ of reperfusion), and deeper (low temperature at $32.6^{\circ} \mathrm{C}$ ) hypothermia. Eventually the body temperatures spontaneously returned to normal levels. 


\section{Infarct Volume and Neurological Deficits}

An infarct volume of $53.9 \%$ was obtained at $48 \mathrm{~h}$ reperfusion after $2 \mathrm{~h} \mathrm{MCAO}$. Infarctions were reduced to $41.6 \%$ and $41.5 \% \mathrm{y}$ $\mathrm{C}+\mathrm{P}$ and $\mathrm{DHC}$ respectively $(\mathrm{p}<0.05)$. With the combination of $\mathrm{C}+\mathrm{P}$ and $\mathrm{DHC}$, infarct volume was significantly further reduced to $27.0 \%$ as compared to untreated stroke $(p<0.01)$ and single treatment group $(p<0.01)$ (Figure 1B, $1 C)$. Neurological deficits in the $2 \mathrm{~h}$ MCAO group followed by $48 \mathrm{~h}$ of reperfusion were determined by the 5 or 12 score systems. Similarly, the combination of C+P and DHC significantly reduced neurological deficits when compared to the untreated $(p<0.01)$ or single treatment groups $(p<0.01)$. $C+P$ alone did not show significant improvement in neurological deficits, while DHC showed an improvement in neurological deficits with only the 12 score scale $(p<0.01)$ (Figure 1D, 1E).

\section{ROS Levels}

Stroke induced a significant increase in ROS production at 6 and $24 \mathrm{~h}$ reperfusion compared to the sham-operated group (reference as 1). C+P or DHC significantly reduced ROS levels at $24 \mathrm{~h}$ after reperfusion, but no significant reductions were observed at $6 \mathrm{~h}$. Combination of C+P and DHC significantly reduced ROS level at both $6(p<0.05)$ and $24 \mathrm{~h}(p<0.01)$ after reperfusion (Figure 2A, 2B).

\section{NOX Activity}

Similarly, a significantly elevation of NOX activity was observed at 6 and $24 \mathrm{~h}$ of reperfusion compared to the sham-operated group (reference as 1), which was reversed by C+P treatment ( $p<0.05$ for $6 h ; p<0.01$ for $24 h$ ) and the combination treatment ( $p<0.01$ for both groups). DHC, however, did not reduced NOX activity (Figure 2C, 2D).

\section{Apoptotic Cell Death}

Apoptotic cell death was greatly increased in the stroke group compared to the sham-operated group (reference as 1). DHC decreased cell death at $6(p<0.05)$ and $24 \mathrm{~h}(\mathrm{p}<0.01)$ of reperfusion, while $C+P$ alone did not. Again, combination of $C+P$ and DHC further decreased cell death ( $p<0.01$ for 6 and 24 h) (Figure 2E, 2F).

\section{Lactate level}

Compared to the sham-operated group (reference as 1), lactate was significantly increased after stroke. Both C+P and DHC alone decreased lactate levels at 6 ( $p<0.05$ for $C+P$ and $D H C)$ and $24 \mathrm{~h}$ ( $p<0.05$ for $C+P ; p<0.01$ for DHC) of reperfusion. Again, the combination treatment enhanced lactate reduction at 6 and $24 \mathrm{~h}(\mathrm{p}<0.01)$ as compared to $C+P$ alone at $24 \mathrm{~h}(\mathrm{p}<0.05)$ and DHC alone at $6 \mathrm{~h}(\mathrm{p}<0.05)$ of reperfusion. (Figure 3A, 3B).

\section{Cerebral Glucose Concentration}

A significant increase of cerebral glucose level was observed after stroke as compared to the sham-operated group, suggesting hyperglycemia. DHC decreased cerebral glucose levels at both $6(p<0.01)$ and $24 h(p<0.01)$ reperfusion, while $C+P$ decreased cerebral glucose levels at $6 \mathrm{~h}(\mathrm{p}<0.01)$. The combination treatment greatly decreased cerebral glucose levels at 6 and $24 \mathrm{~h}(\mathrm{p}<0.01)$ as compared to C+P alone at $24 \mathrm{~h}(\mathrm{p}<0.05)$ and DHC alone at $6 \mathrm{~h}(\mathrm{p}<0.01)$ (Figure 3C, 3D).

\section{ATP Level}


ATP level was greatly decreased in the stroke group compared to the sham-operated group (reference as 1 ). The combination of C+P and DHC further prevented ATP level depletion at both $6(p<0.05)$ and $24 \mathrm{~h}(\mathrm{p}<0.01)$ (Figure 3E, 3F).

\section{Hypothermia Induced Neuroprotection Is Associated with Glucose Mentalism}

To further elucidate whether the mechanism of neuroprotective is related to glucose metabolism after ischemia stroke, the inhibitors of GLUT-1 (phloretin), GLUT-3 (cytochalasin B) and PCK (TZD) were used. As shown in Figure 4, phloretin, cytochalasin B, and TZD significantly decreased the infarct volumes to $29.4 \%, 37.1 \%$ and $25.2 \%$ respectively (Figure 4A, 4B). Similarly, all three inhibitors significantly reduced neurological deficits as measured by 5 and 12 score scales $(p<0.01)$ (Figure 4C, 4D). ROS level were also significantly reduced by phloretin, cytochalasin B, and TZD at $6(p<0.01)$ and $24 \mathrm{~h}$ $(p<0.01$ ) of reperfusion (Figure 4E, 4F). In addition, phloretin, cytochalasin B, and TZD significantly decreased lactate levels at both $6(p<0.01)$ and $24 \mathrm{~h}(\mathrm{p}<0.01)$ of reperfusion (Figure 4G, 4H).

\section{Pharmacological Hypothermia Reduced Expression of Glycolytic Enzyme}

Ischemic rats with $2 \mathrm{~h}$ MCAO exhibited a significant increase in protein levels of PFK, LDH, GLUT-1, and GLUT-3 at 6 and $24 \mathrm{~h}$ of reperfusion as compared to the sham group (referenced as 1) (Figure 5A-I). PFK increase was significantly diminished by C+P alone at $6 \mathrm{~h}(\mathrm{p}<0.05)$ and DHC alone at 6 and $24 \mathrm{~h}(\mathrm{p}<0.05)$, while their combination enhanced the reduction at both 6 $(p<0.01)$ and $24 \mathrm{~h}(\mathrm{p}<0.01)$. Similar patterns were achieved by phloretin and cytochalasin B at both $6(p<0.01)$ and $24 \mathrm{~h}$ ( $p<0.01)$ of reperfusion. Again, LDH level was significantly decreased by C+P at $6 \mathrm{~h}(\mathrm{p}<0.01)$ and DHC at $6(p<0.01)$ and $24 \mathrm{~h}$ $(p<0.01)$, with further enhancement by the combination of C+P and DHC, phloretin, and cytochalasin B at 6 and $24 \mathrm{~h}(\mathrm{p}<0.01)$ (Figure 5B-E). The same trends were observed in GLUT-1 and GLUT-3 protein levels. The combination of C+P and DHC significantly decreased GLUT-1 and GLUT-3 at both $6(p<0.01)$ and $24 \mathrm{~h}(\mathrm{p}<0.05)$ of reperfusion, while DHC only decreased GLUT-1 expression at $6 \mathrm{~h}$ of reperfusion $(p<0.05)$. Phloretin inhibited the expression of GLUT-1 significantly at $6(p<0.01)$ and $24 \mathrm{~h}(\mathrm{p}<0.05)$, while cytochalasin B inhibited the expression of GLUT-1 $(p<0.05)$ and GLUT-3 $(p<0.01)$ at 6 and $24 \mathrm{~h}$ of reperfusion (Figure 5F-I).

\section{Pharmacological Hypothermia Reduced Expression of Gluconeogenic Enzymes}

Ischemic rats with $2 \mathrm{~h}$ MCAO significantly increased PCK1 and PCK2 protein levels at 6 and $24 \mathrm{~h}$ of reperfusion as compared to sham group (referenced as 1) (Figure 6A-E). The increase of PCK1 was significantly reduced by C+P at $24 \mathrm{~h}(\mathrm{p}<0.05)$ and DHC at 6 and $24 \mathrm{~h}(\mathrm{p}<0.05)$. Their combination provided stronger inhibition at both 6 and $24 \mathrm{~h}(\mathrm{p}<0.01)$ of reperfusion. The inhibitive effect was similarly induced by TZD, the PCK inhibitor ( $p<0.01)$ (Figure 6B, 6C). The increase of PCK2 after stroke was significantly reduced by all of the PH protocols at both time points, similar to the effects induced by TZD (p<0.01) (Figure 6D, 6E).

\section{Effect of NOX On The Neuroprotection Induced By Pharmacological Hypothermia}

To further explore whether PH induced neuroprotection was associated with NOX, apocynin (a NOX inhibitor) was applied. The combination of C+P and DHC significantly decreased the protein level of gp91 at $6(p<0.05)$ and $24 \mathrm{~h}(\mathrm{p}<0.01)$ of reperfusion, which was consistent with the effect induced by apocynin $(p<0.01)$ (Figure 7A-C). The key glycolytic enzyme PFK was 
significantly reduced by C+P at $6 \mathrm{~h}(\mathrm{p}<0.05), \mathrm{DHC}$ at 6 and $24 \mathrm{~h}(\mathrm{p}<0.05)$, and the combination of C+P and DHC at both 6 $(p<0.01)$ and $24 \mathrm{~h}(p<0.01)$. These were similar to the reductions induced by apocynin at both 6 and $24 \mathrm{~h}(p<0.05)$ of reperfusion (Figure 7D, 7E). In addition, while the key gluconeogenic enzyme PCK1 was reduced by PH, it was not reduced by apocynin, suggesting that PCK1 was independent from NOX activity (Figure 7F, 7G).

\section{Discussion}

The present study revealed that the combination of C+P $(4 \mathrm{mg} / \mathrm{kg})$ and DHC $(0.5 \mathrm{mg} / \mathrm{kg})$ induced an effective hypothermic state, and that the combination induced an enhanced neuroprotection as compared to each alone. This neuroprotection was evidenced by reduction in infarct volumes, neurological deficits, NOX activity and its subunit gp91, ROS, cell death, glucose, and lactate, with simultaneous increase in ATP levels and improved overall glucose metabolism, with consideration for both hyperglycolysis and gluconeogenesis. The improvement of glucose metabolism with C+P+DHC was evidenced by decreased levels of glycolytic enzymes (GLUT-1, GLUT-3, PFK and LDH), through inhibition of NOX level, and gluconeogenic enzymes (PCK1 and PCK2). These findings support our hypothesis that PH, especially by combination of C+P and DHC, reversed dysfunctional hyperglycolysis and gluconeogenesis induced by stroke, resulting in reduced brain damage.

Systemic hypothermia is a traditional therapeutic hypothermia method to prevent brain cell death from acute ischemic stroke. Early attempts of harnessing hypothermia to prevent brain tissue death from acute ischemic stroke frequently utilized physical means of decreasing the systemic temperature. Clinical limitations of physical hypothermia induction included delays in cooling initiation and the onset of target temperature. The late start necessitated a prolonged hypothermia duration, which in turn required intensive medical support and caused secondary complications such as pneumonia [10]. The only means of physically inducing hypothermia that found significant success was selective hypothermia (or regional cooling), achieved through injecting cool saline in midst of a mechanical thrombectomy procedure [35,36]. While highly effective, this procedure has a stringent inclusion criteria, limiting the patient population that it benefits. Pharmacologic cooling is attractive because of its ease of use. Although it induces systemic hypothermia, pharmacological hypothermia (PH) is a strong stroke therapy candidate that may be able to provide the benefits of cooling without the intense labor, unintended consequences, and limited patient population of physical hypothermia. Furthermore, it also counteracts the physiological resistance to cooling by inhibiting shivering $[37,13]$. While single drugs require toxic doses to achieve therapeutic levels of hypothermia, combinations of lower doses avoid toxicity and work synergistically to achieve efficient cooling [14]. There are eight classes of pharmacological agents that can induce hypothermia, which are the cannabinoid system, Transient Receptor Potential Vanilloid channel 1 (TRPV1) receptor, opioid receptor, neurotensin, thyroxine derivatives, dopamine receptor activators, gaseous hypothermia, and adenosine/adenine nucleotides.

DHC, an analog and congener of capsaicin in chili peppers (Capsicum), is a TRPV1 agonist [38, 39]. TRPV1 is a nonspecific cation channel and confers neuroprotection through its ability to induce hypothermia [37]. Activation of TRPV1 resets thermoregulation into the hypothermic range, which permits effective physiological hypothermia while eliminating concerns for natural rewarming responses such as shivering [40]. The thermoregulation reset is achieved at several brain regions, including the preoptic area of the hypothalamus [41]. However, given the toxicity and complications associated with high doses of DHC that are required to achieve effective hypothermia, its use as monotherapy is limited [42, 43]. Previously, we have demonstrated that a low dose $(0.5 \mathrm{mg} / \mathrm{kg}) \mathrm{DHC}$ combined with physical hypothermia (ice pad) could provide enhanced hypothermia and neuroprotection [43]. Additionally, DHC was seen to act synergistically at low, non-toxic doses with phenothiazine class drugs to induce effective $\mathrm{PH}$ [14].

Chlorpromazine and promethazine (C+P), two members of the phenothiazine class of neuroleptic drugs, have been widely used for their antipsychotic and sedative effects [44]. Previously, we have reported that C+P could confer neuroprotection in stroke via the induction of an "artificial hibernation"-like state, achieved by decreasing brain activity and glucose metabolism

[33]. The depressive effect on glucose utilization is similar to those of local anesthetics [45]. Combining physical hypothermia with C+P significantly enhanced the neuroprotective effects of mild hypothermia [46]. Most importantly, C+P, as members of the phenothiazine class, act synergistically with DHC, inducing hypothermia without concern for toxic doses. 
The mechanism of ischemic damage has been well described. In sufficiently perfused brain tissue, ATP is primarily generated by oxidative phosphorylation in mitochondria [47]. In hypoxic conditions, such as AIS, mitochondrial oxidative phosphorylation is no longer possible. Instead, the ischemic brain tissue depends on glycolysis, a considerably inefficient method compared to the perfused state [48]. Thus, the brain attempts to compensate with excessive glucose uptake through GLUT-1 and GLUT-3 transporters, leading to neuronal injury [31]. This state of increased glucose uptake and metabolism is described as hyperglycemia and hyperglycolysis, which is frequently seen in ischemia/reperfusion injuries and associated with poor outcomes $[49,26,25]$. Pharmacological and physical hypothermia have been seen to target this pathway effectively. Pharmacological hypothermia with DHC and C+P suppressed ROS and lactic acid accumulation and prevented ATP depletion in achieving neuroprotection [14].

In the present study, hyperglycolysis inhibition attenuated brain damage, as observed by the relationship between improved amelioration and decreased glucose, lactate, and PFK. Recent studies indicate that hyperglycolysis-exacerbated injury, especially during reperfusion, is due to activation of NOX, independent of lactic acidosis [50]. NOX is a multi-component (p47 ${ }^{\text {phox }}$, p67 $7^{\text {phox }}, \mathrm{p} 0^{\text {phox }}$ and Rac2) membrane-bound enzyme complex located in both the cytosol and plasma membrane [51]. When NOX is phosphorylated at its $\mathrm{p} 47^{\text {phox }}$ subunit, it forms a complex and translocates to the plasma membrane to dock with specific plasma membrane subunits such as gp91 phox [52]. The catalytic core of the enzyme is composed of gp91 ${ }^{\text {phox }}$ [53]. NOX is dependent on glucose metabolism, specifically the hexose monophosphate shunt, which supplies the NADPH necessary for enzymatic activity [54]. NADPH is a necessary cofactor for NOX as it transfers its electron to $\mathrm{O}_{2}$ to create superoxide $\left(\mathrm{O}_{2}^{-}\right)$[55]. Hence, the presence of glucose during reperfusion increases neuronal NOX activity [56, 57] by functioning as the requisite electron donor for neuronal superoxide production through the generation of NADPH [56]. Moreover, activity of the catalytic subunit, gp91 ${ }^{\text {phox }}$, is dependent on the presence of NADPH produced by glycolysis [56]. After ischemia/reperfusion injury, there may be a time window in which hyperglycolysis-induced NOX activation enhances ROS generation. The present study found that stroke exacerbates NOX activation, ROS generation, and hyperglycolysis, which were reduced by $\mathrm{C}+\mathrm{P}$ and $\mathrm{DHC}$, suggesting that $\mathrm{PH}$ induced neuroprotection via improved glucose metabolism with NOX inhibition.

Inhibiting hyperglycolysis has proven to be therapeutic in contexts other than AIS. In peritoneal dialysis, peritoneal fibrosis is prevented through hyperglycolysis inhibition [58]. In thromboembolic cerebral ischemia, neuroprotection was induced with ethanol and therapeutic hypothermia through hyperglycolysis attenuation [59]. In AIS, various ameliorative therapies were observed to confer benefit while inhibiting hyperglycolysis. Ethanol and modafinil, each of which are known to be neuroprotective, in combination inhibited hyperglycolysis in attenuating AlS damage [24]. Normobaric $\mathrm{O}_{2}$ [25] and ischemic preconditioning [60] modulated signaling pathways to subdue hyperglycolysis in postischemic states. Most relevant to this study, C+P also attenuated hyperglycolysis [26].

More recently, it has been observed that the brain also undergoes gluconeogenesis. One of the crucial means of maintaining glucose levels in humans is gluconeogenesis. The common perception is that gluconeogenic activities are only present in the liver, kidneys, intestines, and muscle tissue. However, many studies have now proven that the brain also undergoes gluconeogenesis in significant levels. While the organs that are classically associated with gluconeogenesis usually overshadow it, the brain is definitely capable of and undergoes gluconeogenesis [19]. This may be the missing link to our understanding of the mechanism of damage induced by AIS. In an attempt to compensate for ATP depletion, the ischemic brain tissue initiates gluconeogenesis. However, due to ATP depletion, gluconeogenesis is incomplete and results in undesirable byproduct of lactic acid instead. The consequence of dysfunctional gluconeogenesis of the ischemic brain tissue is an excessively active phosphoenolpyruvate carboxy kinase (PCK) enzyme, which contributes to the neurotoxic pathways of lactic acid and ROS accumulation [19]. In ischemia, when mitochondrial oxidative phosphorylation and ATP production are disrupted, anaerobic glycolysis becomes the primary source of ATP. Anaerobic glycolysis alone cannot produce sufficient ATP to maintain brain function and produces lactate, leading to acidosis and ROS. In an attempt to compensate for insufficient energy, we see a full circle where gluconeogenesis is increasingly attempted after ischemia to provide additional substrate for energy production, which may not function correctly due to lack of ATP [19], leading to excess lactic acidosis. We must note that gluconeogenesis is anabolic, which increases the amount of glucose, while oxidative phosphorylation is catabolic and 
decreases the amount of glucose. In our previous study, cerebral gluconeogenesis was actively found after stroke [20]. In the present study, we further found C+P and DHC conferred neuroprotection partially through inhibition of cerebral gluconeogenesis evidenced by PCK enzymes.

In conclusion, the present study found that PH was effective in conferring therapy to rats undergoing AIS through a pathway involving prevention of dysfunctional gluconeogenesis and hyperglycolysis. These findings justify the exploration of new therapies that target gluconeogenesis, not only in stroke patients, but also in other forms of brain injuries such as trauma and epilepsy.

\section{Declarations}

\section{Acknowledgements}

Not applicable.

\section{Author contributions}

Longfei Guan, Fengwu Li and Changya Peng conducted the experiments and data analyses. Longfei Guan, Hangil Lee, Jiamei Shen, Yu Ji and Huishan Du helped with revision of the manuscript. Xiaokun Geng and Yuchuan Ding developed the study concept and supervised the study. The content of this manuscript has been reviewed, read, and agreed upon by all designated authors.

\section{Funding}

This work was supported in part by a Merit Review Award (101RX-001964-01) from the US Department of Veterans Affairs Rehabilitation R\&D Service, the National Nature Science Foundation of China (No. 81871838 and 81802231 ), Beijing Tongzhou District Financial Fund, and the Science and Technology Plan of Beijing Tongzhou District (KJ2018CX006).

\section{Data availability statement}

The raw data supporting the conclusions of this article will be made available available from the corresponding author upon reasonable request

\section{Ethics statement}

The animal study was reviewed and approved by the Animal Investigation Committee of Capital Medical University.

\section{Conflicts of Interests}

The authors declare that they have no conflicts of interest.

\section{Consent to Participate}

No human subjects were involved in this research, so consent to participate is not relevant.

\section{Consent for Publication}


All authors have approved this manuscript and consented to its submission for publication.

\section{References}

1. Campbell BCV, De Silva DA, Macleod MR, Coutts SB, Schwamm LH, Davis SM, Donnan GA (2019) Ischaemic stroke. Nature Reviews Disease Primers 5(1):70. doi:10.1038/s41572-019-0118-8

2. Donkor ES (2018) Stroke in the 21(st) Century: A Snapshot of the Burden, Epidemiology, and Quality of Life. Stroke Res Treat 2018:3238165. doi:10.1155/2018/3238165

3. Rabinstein AA (2020) Update on Treatment of Acute Ischemic Stroke. Continuum (Minneap Minn) 26(2):268-286. doi: $10.1212 /$ con. 0000000000000840

4. Albers GW, Marks MP, Kemp S, Christensen S, Tsai JP, Ortega-Gutierrez S, McTaggart RA, Torbey MT, Kim-Tenser M, LeslieMazwi T, Sarraj A, Kasner SE (2018) Thrombectomy for Stroke at 6 to 16 Hours with Selection by Perfusion Imaging. N Engl J Med 378(8):708-718. doi:10.1056/NEJMoa1713973

5. Knecht T, Borlongan C, Dela Peña I (2018) Combination therapy for ischemic stroke: Novel approaches to lengthen therapeutic window of tissue plasminogen activator. Brain Circ 4(3):99-108. doi:10.4103/bc.bc_21_18

6. Katan M, Luft A (2018) Global Burden of Stroke. Semin Neurol 38(2):208-211. doi:10.1055/s-0038-1649503

7. Savitz SI, Baron JC, Fisher M (2019) Stroke Treatment Academic Industry Roundtable X: Brain Cytoprotection Therapies in the Reperfusion Era. Stroke 50(4):1026-1031. doi:10.1161/strokeaha.118.023927

8. Lyden P, Buchan A, Boltze J, Fisher M (2021) Top Priorities for Cerebroprotective Studies: A Paradigm Shift. Stroke:Strokeaha121034947. doi:10.1161/strokeaha.121.034947

9. Kuczynski AM, Demchuk AM, Almekhlafi MA (2019) Therapeutic hypothermia: Applications in adults with acute ischemic stroke. Brain Circ 5(2):43-54. doi:10.4103/bc.bc_5_19

10. Wu L, Wu D, Yang T, Xu J, Chen J, Wang L, Xu S, Zhao W, Wu C, Ji X (2020) Hypothermic neuroprotection against acute ischemic stroke: The 2019 update. J Cereb Blood Flow Metab 40(3):461-481. doi:10.1177/0271678x19894869

11. Kurisu K, Kim JY, You J, Yenari MA (2019) Therapeutic Hypothermia and Neuroprotection in Acute Neurological Disease. Curr Med Chem 26(29):5430-5455. doi:10.2174/0929867326666190506124836

12. Lee H, Ding $Y(2020)$ Temporal limits of therapeutic hypothermia onset in clinical trials for acute ischemic stroke: How early is early enough? Brain Circ 6(3):139-144. doi:10.4103/bc.bc_31_20

13. Liu K, Khan H, Geng X, Zhang J, Ding Y (2016) Pharmacological hypothermia: a potential for future stroke therapy? Neurol Res 38(6):478-490. doi:10.1080/01616412.2016.1187826

14. Han Y, Geng X-k, Lee H, Li F, Ding Y (2021) Neuroprotective Effects of Early Hypothermia Induced by Phenothiazines and DHC in Ischemic Stroke. Evidence-Based Complementary and Alternative Medicine 2021:1207092. doi:10.1155/2021/1207092

15. Mohammed M, Madden CJ (2018) Activation of TRPV1 in nucleus tractus solitarius reduces brown adipose tissue thermogenesis, arterial pressure, and heart rate. 315:R134-r143. 10.1152/ajpregu.00049.2018. 1

16. Geng X, Parmar S, Li X, Peng C, Ji X, Chakraborty T, Li WA, Du H, Tan X, Ling F, Guthikonda M, Rafols JA, Ding Y (2013) Reduced apoptosis by combining normobaric oxygenation with ethanol in transient ischemic stroke. Brain Res 1531:1724. doi:10.1016/j.brainres.2013.07.051

17. Kurisu K, Yenari MA (2018) Therapeutic hypothermia for ischemic stroke; pathophysiology and future promise. Neuropharmacology 134 (Pt B) 302-309. doi:10.1016/j.neuropharm.2017.08.025

18. Li WA, Moore-Langston S, Chakraborty T, Rafols JA, Conti AC, Ding Y (2013) Hyperglycemia in stroke and possible treatments. Neurol Res 35(5):479-491. doi:10.1179/1743132813y.0000000209

19. Yip J, Geng X, Shen J, Ding Y (2016) Cerebral Gluconeogenesis and Diseases. Front Pharmacol 7:521. doi:10.3389/fphar.2016.00521 
20. Geng X, Shen J, Li F, Yip J, Guan L, Rajah G, Peng C, DeGracia D, Ding Y (2021) Phosphoenolpyruvate Carboxykinase (PCK) in the Brain Gluconeogenic Pathway Contributes to Oxidative and Lactic Injury After Stroke. Mol Neurobiol. doi:10.1007/s12035-020-02251-3

21. Balança B, Meiller A, Bezin L, Dreier JP, Marinesco S, Lieutaud T (2017) Altered hypermetabolic response to cortical spreading depolarizations after traumatic brain injury in rats. J Cereb Blood Flow Metab 37(5):1670-1686. doi:10.1177/0271678x16657571

22. Amorini AM, Lazzarino G, Di Pietro V, Signoretti S, Lazzarino G, Belli A, Tavazzi B (2016) Metabolic, enzymatic and gene involvement in cerebral glucose dysmetabolism after traumatic brain injury. Biochim Biophys Acta 1862(4):679-687. doi:10.1016/j.bbadis.2016.01.023

23. Xu XJ, Yang MS, Zhang B, Niu F, Dong JQ, Liu BY (2021) Glucose metabolism: A link between traumatic brain injury and Alzheimer's disease. Chin J Traumatol 24(1):5-10. doi:10.1016/j.cjtee.2020.10.001

24. Abbasi Y, Shabani R, Mousavizadeh K, Soleimani M, Mehdizadeh M (2019) Neuroprotective effect of ethanol and Modafinil on focal cerebral ischemia in rats. Metab Brain Dis 34(3):805-819. doi:10.1007/s11011-018-0378-0

25. Cheng Z, Li FW, Stone CR, Elkin K, Peng CY, Bardhi R, Geng XK, Ding YC (2021) Normobaric oxygen therapy attenuates hyperglycolysis in ischemic stroke. Neural Regen Res 16(6):1017-1023. doi:10.4103/1673-5374.300452

26. Guo S, Cosky E, Li F, Guan L, Ji Y, Wei W, Peng C, Geng X, Ding Y (2021) An inhibitory and beneficial effect of chlorpromazine and promethazine $(\mathrm{C}+\mathrm{P})$ on hyperglycolysis through HIF-1a regulation in ischemic stroke. Brain Res 1763:147463. doi:10.1016/j.brainres.2021.147463

27. Geng X, Li F, Yip J, Peng C, Elmadhoun O, Shen J, Ji X, Ding Y (2017) Neuroprotection by Chlorpromazine and Promethazine in Severe Transient and Permanent Ischemic Stroke. Mol Neurobiol 54(10):8140-8150. doi:10.1007/s12035-016-0280-x

28. Wang F, Wang Y, Geng X, Asmaro K, Peng C, Sullivan JM, Ding JY, Ji X, Ding Y (2012) Neuroprotective effect of acute ethanol administration in a rat with transient cerebral ischemia. Stroke 43(1):205-210.

doi:10.1161/strokeaha.111.629576

29. Longa EZ, Weinstein PR, Carlson S, Cummins R (1989) Reversible middle cerebral artery occlusion without craniectomy in rats. Stroke 20(1):84-91. doi:10.1161/01.str.20.1.84

30. Belayev L, Alonso OF, Busto R, Zhao W, Ginsberg MD (1996) Middle cerebral artery occlusion in the rat by intraluminal suture. Neurological and pathological evaluation of an improved model. Stroke 27(9):1616-1622. discussion 1623 doi:10.1161/01.str.27.9.1616

31. Kochanski R, Peng C, Higashida T, Geng X, Hüttemann M, Guthikonda M, Ding Y (2013) Neuroprotection conferred by post-ischemia ethanol therapy in experimental stroke: an inhibitory effect on hyperglycolysis and NADPH oxidase activation. J Neurochem 126(1):113-121. doi:10.1111/jnc.12169

32. Geng X, Fu P, Ji X, Peng C, Fredrickson V, Sy C, Meng R, Ling F, Du H, Tan X, Hüttemann M, Guthikonda M, Ding Y (2013) Synergetic neuroprotection of normobaric oxygenation and ethanol in ischemic stroke through improved oxidative mechanism. Stroke 44(5):1418-1425. doi:10.1161/strokeaha.111.000315

33. Guan L, Guo S, Yip J, Elkin KB, Li F, Peng C, Geng X, Ding Y (2019) Artificial Hibernation by Phenothiazines: A Potential Neuroprotective Therapy Against Cerebral Inflammation in Stroke. Curr Neurovasc Res 16(3):232-240. doi:10.2174/1567202616666190624122727

34. Haelewyn B, Yvon A, Hanouz JL, MacKenzie ET, Ducouret P, Gérard JL, Roussel S (2003) Desflurane affords greater protection than halothane against focal cerebral ischaemia in the rat. $\mathrm{Br} \mathrm{J}$ Anaesth 91(3):390-396. doi:10.1093/bja/aeg186

35. Wu C, Zhao W, An H, Wu L, Chen J, Hussain M, Ding Y, Li C, Wei W, Duan J, Wang C, Yang Q, Wu D, Liu L, Ji X (2018) Safety, feasibility, and potential efficacy of intraarterial selective cooling infusion for stroke patients treated with mechanical thrombectomy. J Cereb Blood Flow Metab 38(12):2251-2260. doi:10.1177/0271678x18790139 
36. Ding Y, Li J, Rafols JA, Phillis JW, Diaz FG (2002) Prereperfusion saline infusion into ischemic territory reduces inflammatory injury after transient middle cerebral artery occlusion in rats. Stroke 33(10):2492-2498.

doi:10.1161/01.str.0000028237.15541.cc

37. Ding Z, Cowan A, Tallarida R, Rawls SM (2006) Capsaicin and nitric oxide synthase inhibitor interact to evoke a hypothermic synergy. Neurosci Lett 409(1):41-46. doi:10.1016/j.neulet.2006.09.018

38. Cao Z, Balasubramanian A, Marrelli SP (2014) Pharmacologically induced hypothermia via TRPV1 channel agonism provides neuroprotection following ischemic stroke when initiated 90 min after reperfusion. Am J Physiol Regul Integr Comp Physiol 306(2):R149-R156. doi:10.1152/ajpregu.00329.2013

39. Fosgerau K, Weber UJ, Gotfredsen JW, Jayatissa M, Buus C, Kristensen NB, Vestergaard M, Teschendorf P, Schneider A, Hansen P, Rauns $\varnothing$ J, Køber L, Torp-Pedersen C, Videbaek C (2010) Drug-induced mild therapeutic hypothermia obtained by administration of a transient receptor potential vanilloid type 1 agonist. BMC Cardiovasc Disord 10:51. doi:10.1186/14712261-10-51

40. Rawls SM, Benamar K (2011) Effects of opioids, cannabinoids, and vanilloids on body temperature. Front Biosci (Schol Ed) 3:822-845. doi:10.2741/190

41. Ota W, Nakane Y, Kashio M, Suzuki Y, Nakamura K, Mori Y, Tominaga M, Yoshimura T (2019) Involvement of TRPM2 and TRPM8 in temperature-dependent masking behavior. Sci Rep 9(1):3706. doi:10.1038/s41598-019-40067-X

42. Zhang M, Wang H, Zhao J, Chen C, Leak RK, Xu Y, Vosler P, Chen J, Gao Y, Zhang F (2013) Drug-induced hypothermia in stroke models: does it always protect? CNS Neurol Disord Drug Targets 12(3):371-380.

doi:10.2174/1871527311312030010

43. Zhang J, Liu K, Elmadhoun O, Ji X, Duan Y, Shi J, He X, Liu X, Wu D, Che R, Geng X, Ding Y (2018) Synergistically Induced Hypothermia and Enhanced Neuroprotection by Pharmacological and Physical Approaches in Stroke. Aging Dis 9(4):578-589. doi:10.14336/ad.2017.0817

44. Ban TA (2007) Fifty years chlorpromazine: a historical perspective. Neuropsychiatr Dis Treat 3(4):495-500

45. Uesono Y, Toh-e A, Kikuchi Y, Araki T, Hachiya T, Watanabe CK, Noguchi K, Terashima I (2016) Local Anesthetics and Antipsychotic Phenothiazines Interact Nonspecifically with Membranes and Inhibit Hexose Transporters in Yeast. Genetics 202(3):997-1012. doi:10.1534/genetics.115.183806

46. An H, Duan Y, Wu D, Yip J, Elmadhoun O, Wright JC, Shi W, Liu K, He X, Shi J, Jiang F, Ji X, Ding Y (2017) Phenothiazines Enhance Mild Hypothermia-induced Neuroprotection via PI3K/Akt Regulation in Experimental Stroke. Sci Rep 7(1):7469. doi:10.1038/s41598-017-06752-5

47. Protasoni M, Zeviani M (2021) Mitochondrial Structure and Bioenergetics in Normal and Disease Conditions. Int J Mol Sci 22(2). doi:10.3390/ijms22020586

48. Rich PR (2003) The molecular machinery of Keilin's respiratory chain. Biochem Soc Trans 31(Pt 6):1095-1105. doi:10.1042/bst0311095

49. Zhang S, Zuo W, Guo XF, He WB, Chen NH (2014) Cerebral glucose transporter: the possible therapeutic target for ischemic stroke. Neurochem Int 70:22-29. doi:10.1016/j.neuint.2014.03.007

50. Yenari MA, Kauppinen TM, Swanson RA (2010) Microglial activation in stroke: therapeutic targets. Neurotherapeutics 7(4):378-391. doi:10.1016/j.nurt.2010.07.005

51. Tang XN, Zheng Z, Giffard RG, Yenari MA (2011) Significance of marrow-derived nicotinamide adenine dinucleotide phosphate oxidase in experimental ischemic stroke. Ann Neurol 70(4):606-615. doi:10.1002/ana.22476

52. Rastogi R, Geng X, Li F, Ding Y (2016) NOX Activation by Subunit Interaction and Underlying Mechanisms in Disease. Front Cell Neurosci 10:301. doi:10.3389/fncel.2016.00301

53. Raad H, Mouawia H, Hassan H, El-Seblani M, Arabi-Derkawi R, Boussetta T, Gougerot-Pocidalo MA, Dang PM, El-Benna J (2020) The protein kinase A negatively regulates reactive oxygen species production by phosphorylating gp91phox/NOX2 in human neutrophils. Free Radic Biol Med 160:19-27. doi:10.1016/j.freeradbiomed.2020.07.021 
54. Shen J, Rastogi R, Geng X, Ding Y (2019) Nicotinamide adenine dinucleotide phosphate oxidase activation and neuronal death after ischemic stroke. Neural Regen Res 14(6):948-953. doi:10.4103/1673-5374.250568

55. Sumimoto H, Minakami R, Miyano K (2019) Soluble Regulatory Proteins for Activation of NOX Family NADPH Oxidases. Methods Mol Biol 1982:121-137. doi:10.1007/978-1-4939-9424-3_8

56. Suh SW, Shin BS, Ma H, Van Hoecke M, Brennan AM, Yenari MA, Swanson RA (2008) Glucose and NADPH oxidase drive neuronal superoxide formation in stroke. Ann Neurol 64(6):654-663. doi:10.1002/ana.21511

57. Tang XN, Cairns B, Kim JY, Yenari MA (2012) NADPH oxidase in stroke and cerebrovascular disease. Neurol Res 34(4):338-345. doi:10.1179/1743132812y.0000000021

58. Si M, Wang Q, Li Y, Lin H, Luo D, Zhao W, Dou X, Liu J, Zhang H, Huang Y, Lou T, Hu Z, Peng H (2019) Inhibition of hyperglycolysis in mesothelial cells prevents peritoneal fibrosis. Sci Transl Med 11(495).

doi:10.1126/scitransImed.aav5341

59. Cai L, Stevenson J, Peng C, Xin R, Rastogi R, Liu K, Geng X, Gao Z, Ji X, Rafols JA, Ji Z, Ding Y (2016) Adjuvant therapies using normobaric oxygen with hypothermia or ethanol for reducing hyperglycolysis in thromboembolic cerebral ischemia. Neuroscience 318:45-57. doi:10.1016/j.neuroscience.2016.01.010

60. Geng J, Zhang Y, Li S, Li S, Wang J, Wang H, Aa J, Wang G (2019) Metabolomic Profiling Reveals That Reprogramming of Cerebral Glucose Metabolism Is Involved in Ischemic Preconditioning-Induced Neuroprotection in a Rodent Model of Ischemic Stroke. J Proteome Res 18(1):57-68. doi:10.1021/acs.jproteome.8b00339

\section{Tables}

Table 1. Physiologic Parameters during Transient MCA Occlusion 
$\begin{array}{llllllll}\begin{array}{l}\text { Physiologic } \\ \text { Parameters }\end{array} & \text { Stroke } & \text { C+P } & \text { DHC } & \text { C+P+DHC } & \text { Phloretin } & \begin{array}{l}\text { Cytochalasin } \\ \text { B TZD }\end{array} & \text { Apocynin }\end{array}$

MAP

\begin{tabular}{ccccccccc} 
Pre MCAO & $88.9 \pm 2.9$ & $86.4 \pm 2.8$ & $83.3 \pm 4.2$ & $83.9 \pm 1.9$ & $84.5 \pm 2.5$ & $87.3 \pm 2.9$ & $88.0 \pm 3.2$ & $86.8 \pm 2.2$ \\
\hline $\begin{array}{c}\text { Pre } \\
\text { reperfusion }\end{array}$ & $88.0 \pm 2.3$ & $86.6 \pm 2.3$ & $87.0 \pm 2.6$ & $87.1 \pm 1.6$ & $85.6 \pm 2.3$ & $86.2 \pm 2.3$ & $85.1 \pm 2.3$ & $86.2 \pm 2.3$ \\
\hline $\begin{array}{c}2 \mathrm{~h} \text { after } \\
\text { reperfusion }\end{array}$ & $80.2 \pm 3.1$ & $86.8 \pm 2.7$ & $83.8 \pm 3.5$ & $82.2 \pm 2.8$ & $83.8 \pm 2.8$ & $84.8 \pm 2.7$ & $83.2 \pm 3.3$ & $85.8 \pm 3.4$ \\
\hline
\end{tabular}

$\mathrm{PH}$

\begin{tabular}{cccccccccc}
\hline Pre MCAO & $7.41 \pm 0.02$ & $7.39 \pm 0.02$ & $7.38 \pm 0.01$ & $7.42 \pm 0.02$ & $7.40 \pm 0.02$ & $7.43 \pm 0.03$ & $7.40 \pm 0.02$ & $7.39 \pm 0.02$ \\
$\begin{array}{c}\text { Pre } \\
\text { reperfusion }\end{array}$ & $7.36 \pm 0.02$ & $7.39 \pm 0.02$ & $7.38 \pm 0.03$ & $7.39 \pm 0.03$ & $7.39 \pm 0.02$ & $7.38 \pm 0.03$ & $7.37 \pm 0.02$ & $7.38 \pm 0.02$ \\
$\begin{array}{c}2 \mathrm{~h} \text { after } \\
\text { reperfusion }\end{array}$ & $7.39 \pm 0.03$ & $7.35 \pm 0.03$ & $7.40 \pm 0.02$ & $7.38 \pm 0.03$ & $7.36 \pm 0.03$ & $7.37 \pm 0.02$ & $7.38 \pm 0.03$ & $7.36 \pm 0.03$ \\
\hline
\end{tabular}

$\mathrm{PO}_{2}$

\begin{tabular}{ccccccccc}
\hline Pre MCAO & $130.9 \pm 6.4$ & $138.9 \pm 5.6$ & $134.2 \pm 4.9$ & $138.5 \pm 6.1$ & $140.9 \pm 7.1$ & $132.9 \pm 7.1$ & $140.8 \pm 6.4$ & $141.9 \pm 7.1$ \\
\hline $\begin{array}{c}\text { Pre } \\
\text { reperfusion }\end{array}$ & $133.9 \pm 4.8$ & $134.6 \pm 5.8$ & $135.9 \pm 4.0$ & $130.9 \pm 4.3$ & $135.6 \pm 3.8$ & $137.6 \pm 4.6$ & $136.4 \pm 2.9$ & $138.6 \pm 5.2$ \\
\hline $\begin{array}{c}2 \mathrm{~h} \text { after } \\
\text { reperfusion }\end{array}$ & $141.1 \pm 6.9$ & $134.7 \pm 4.7$ & $130.1 \pm 3.5$ & $133.1 \pm 6.7$ & $135.7 \pm 4.2$ & $135.1 \pm 5.7$ & $129.1 \pm 4.6$ & $135.9 \pm 6.7$ \\
\hline
\end{tabular}

$\mathrm{PCO}_{2}$

\begin{tabular}{|ccccccccc}
\hline Pre MCAO & $45.5 \pm 2.1$ & $43.9 \pm 2.2$ & $48.0 \pm 4.1$ & $47.5 \pm 3.1$ & $45.5 \pm 2.2$ & $46.3 \pm 4.1$ & $45.9 \pm 2.2$ & $44.8 \pm 3.5$ \\
\hline $\begin{array}{c}\text { Pre } \\
\text { reperfusion }\end{array}$ & $42.8 \pm 1.5$ & $46.7 \pm 1.9$ & $42.4 \pm 2.6$ & $46.8 \pm 3.4$ & $44.7 \pm 1.9$ & $43.4 \pm 2.6$ & $45.8 \pm 1.5$ & $45.7 \pm 2.3$ \\
\hline $\begin{array}{c}2 \mathrm{~h} \text { after } \\
\text { reperfusion }\end{array}$ & $49.3 \pm 2.3$ & $46.6 \pm 4.5$ & $45.2 \pm 2.3$ & $49.5 \pm 2.7$ & $47.6 \pm 3.5$ & $46.0 \pm 2.2$ & $47.3 \pm 3.3$ & $45.8 \pm 3.5$ \\
\hline
\end{tabular}

\section{Figures}


A

B

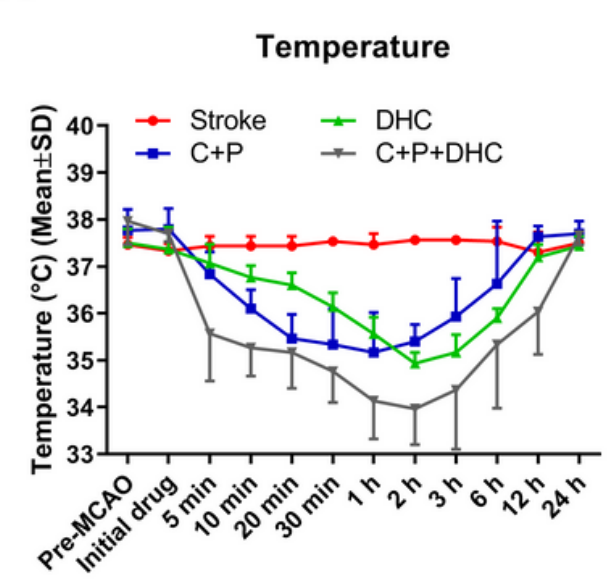

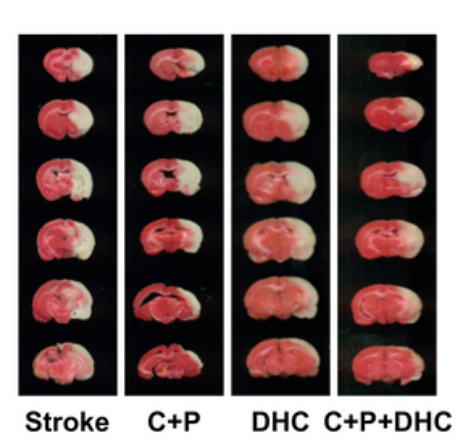

C
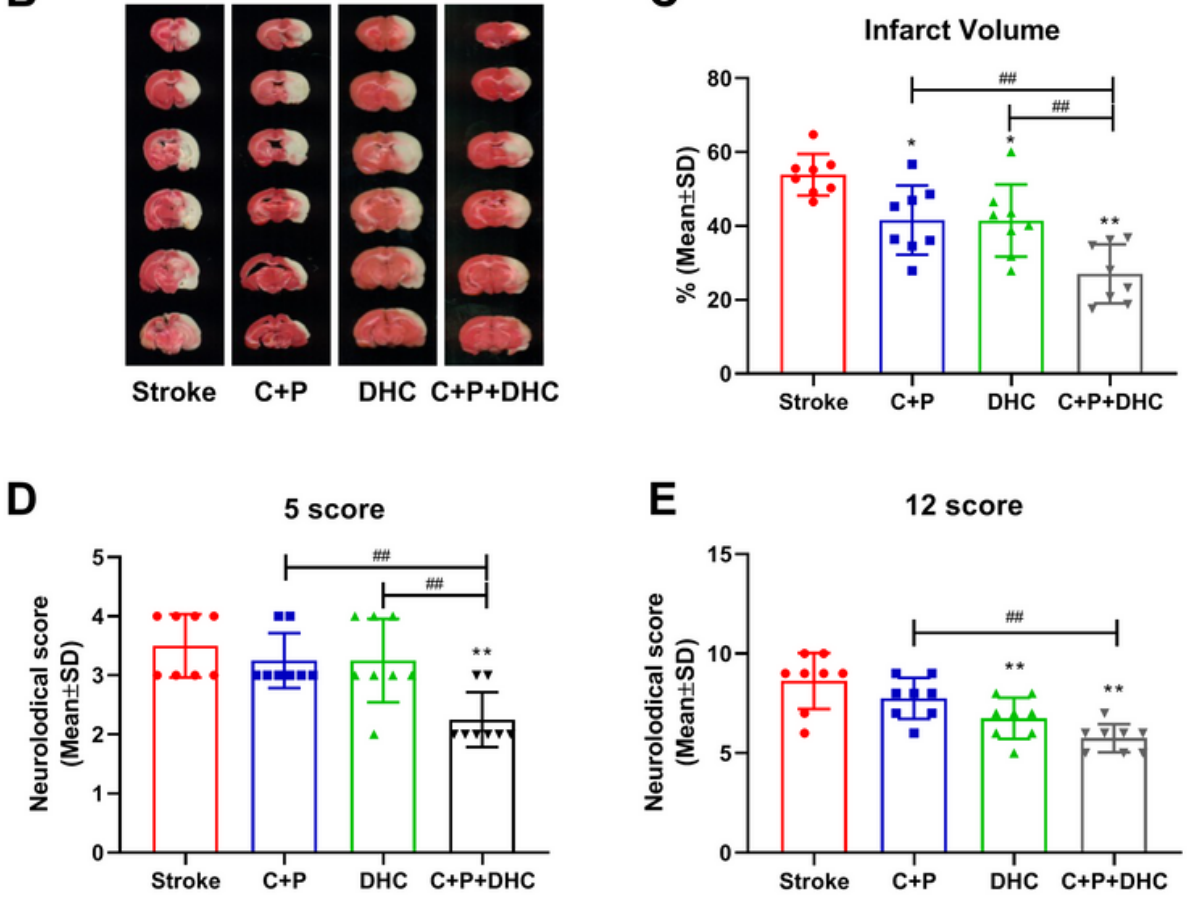

E

12 score

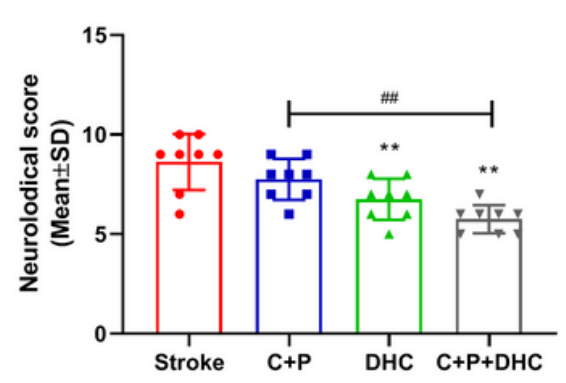

Figure 1

Induction of pharmacological hypothermia and its neuroprotective effects in rat MCAO models. (A) Body temperature before and after the model development with different treatments. Body temperature reached the lowest target of $35.2^{\circ} \mathrm{C}$ by $\mathrm{C}+\mathrm{P}$, $34.9^{\circ} \mathrm{C}$ by DHC, $34^{\circ} \mathrm{C}$ by C+P+DHC. (B) Representative brain slices stained with TTC after $2 \mathrm{~h}$ MCAO and $48 \mathrm{~h}$ of reperfusion. (C) Graphic quantification of TTC sections revealing that $C+P+D H C$ result in significantly decreased in infarct volume. Neurological deficits after $2 \mathrm{~h} \mathrm{MCAO}$ and C+P, DHC, or C+P+DHC therapy using the 5 score system (D) and 12 score system (E) $\mathrm{C}+\mathrm{P}+\mathrm{DHC}$ combination therapy significantly reduced neurological deficits. Data are presented as mean $\pm S D,{ }^{*} p<0.05,{ }^{* *} p<$ 0.01 as compared to stroke group; \#\#p < 0.01 as compared to C+P or DHC alone. 
A

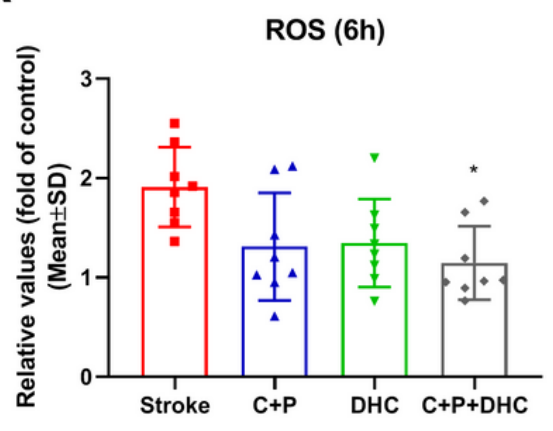

C

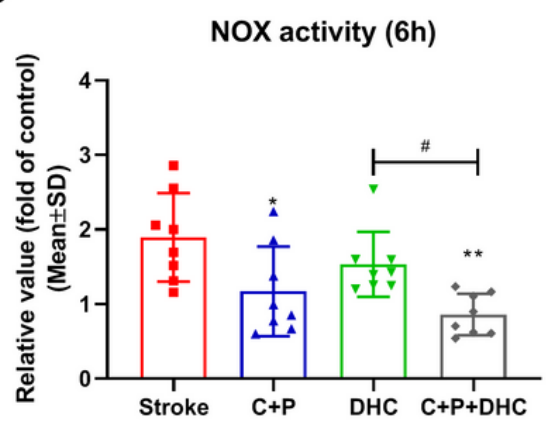

E

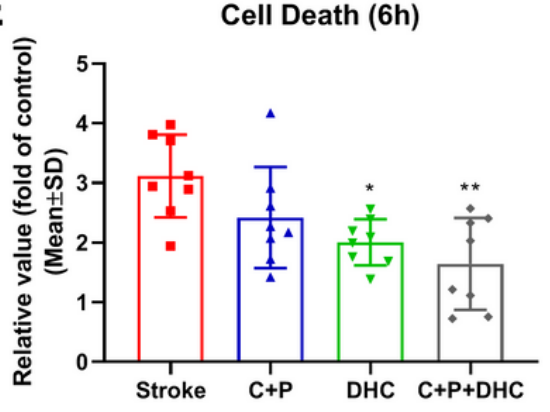

B

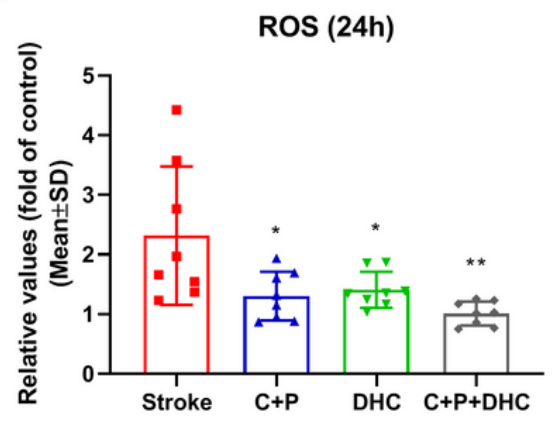

D

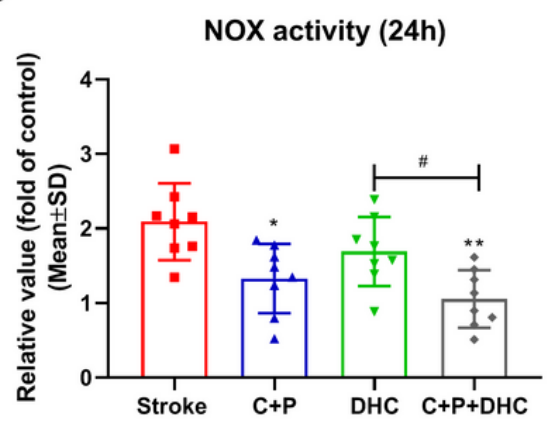

$\mathbf{F}$

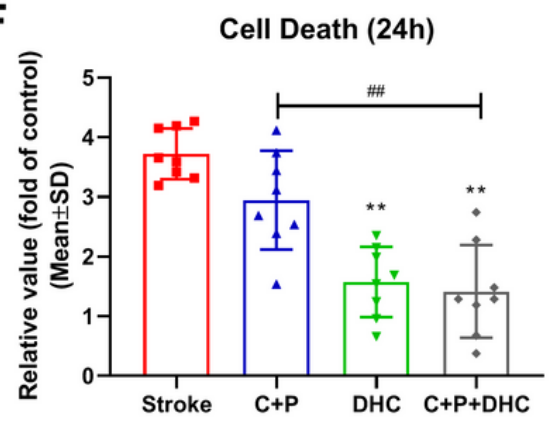

Figure 2

Effect of pharmacological hypothermia on ROS, NOX activity and cell death in rat with $2 \mathrm{~h}$ MCAO. Stroke increased ROS levels, which was significantly reduced by the combination of C+P and DHC at both $6(\mathrm{~A})$ and $24 \mathrm{~h}(\mathrm{~B})$ after reperfusion. While $\mathrm{C}+\mathrm{P}$ or DHC significantly reduced ROS level at $24 \mathrm{~h}$ and no significance reduction observed at $6 \mathrm{~h}$ after reperfusion. NOX activity was significantly increased after stroke at $6(C)$ and $24 \mathrm{~h}(\mathrm{D})$ of reperfusion, which was reversed by $\mathrm{C}+\mathrm{P}$ or the combination of $\mathrm{C}+\mathrm{P}$ and DHC treatment. Apoptotic cell death significantly increased at $6(E)$ and $24 \mathrm{~h}(\mathrm{~F})$ of reperfusion. DHC or combination of $\mathrm{C}+\mathrm{P}$ and $\mathrm{DHC}$ significantly reduced the cell death, while C+P alone did not. Data are presented as mean $\pm S D,{ }^{*} \mathrm{p}<0.05$, ${ }^{* *} \mathrm{p}<$ 0.01 as compared to stroke group; \#p $<0.05$ as compared to C+P or DHC alone. 
A

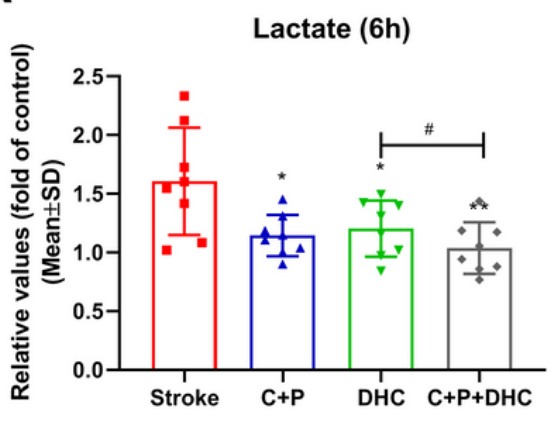

C

Brain glucose $(6 \mathrm{~h})$

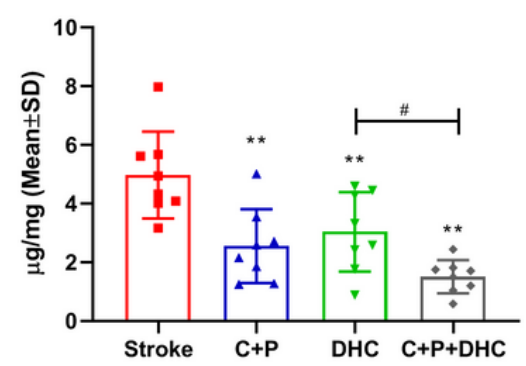

$\mathbf{E}$

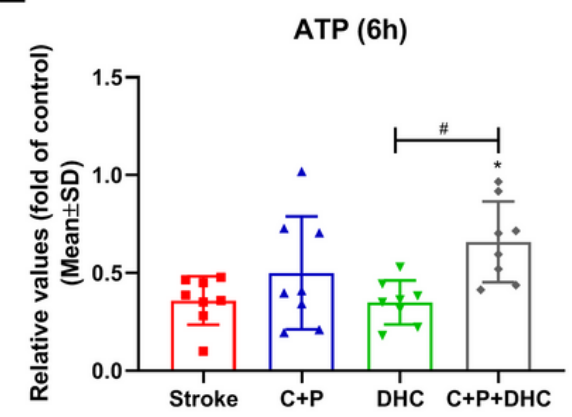

B

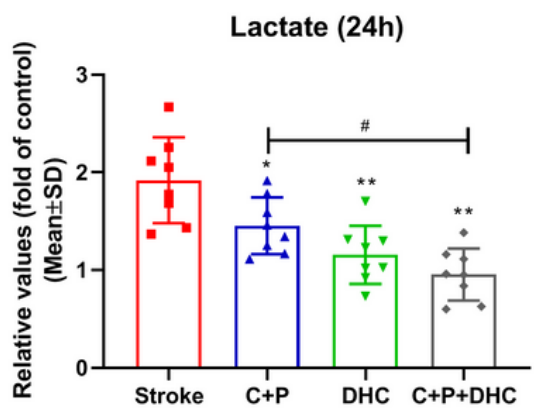

D

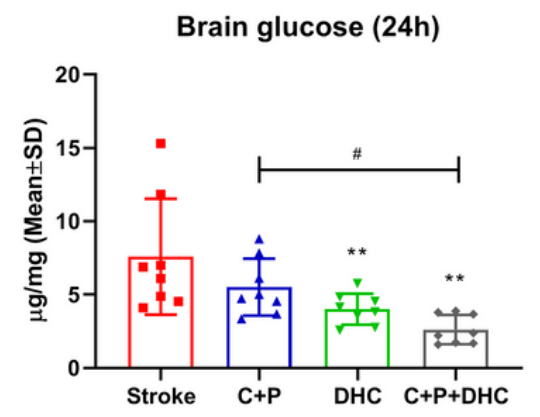

$\mathbf{F}$

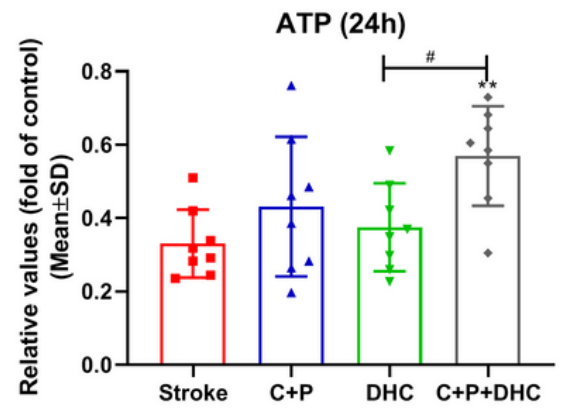

Figure 3

Effect of pharmacological hypothermia on lactate, glucose and ATP level in rat with $2 \mathrm{~h} \mathrm{MCAO.} \mathrm{Lactate} \mathrm{level} \mathrm{was} \mathrm{significantly}$ increased after stroke, which was significantly reduced by C+P, DHC, or the combination C+P and DHC treatment at both 6 (A) and $24 \mathrm{~h}(\mathrm{~B})$ after reperfusion. Brain glucose levels increased at $6(C)$ and $24 \mathrm{~h}(\mathrm{D})$ of reperfusion. DHC or the combination $\mathrm{C}+\mathrm{P}$ and DHC decreased brain glucose level at both 6 and $24 \mathrm{~h}$ of reperfusion, while C+P decreased brain glucose level at $6 \mathrm{~h}$ of reperfusion. Stroke reduced ATP levels, only the combination therapy significantly increased ATP levels at both $6(E)$ and 24 $h(F)$ after reperfusion. Data are presented as mean $\pm S D$, ${ }^{*} p<0.05$, ** $p<0.01$ as compared to stroke group; $\# p<0.05$ as compared to $\mathrm{C}+\mathrm{P}$ or $\mathrm{DHC}$ alone. 
A

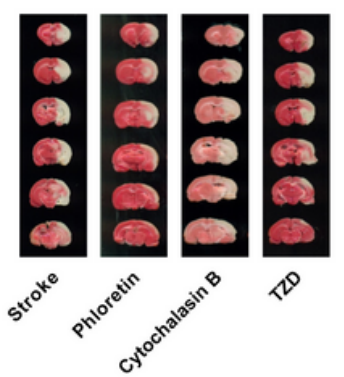

E

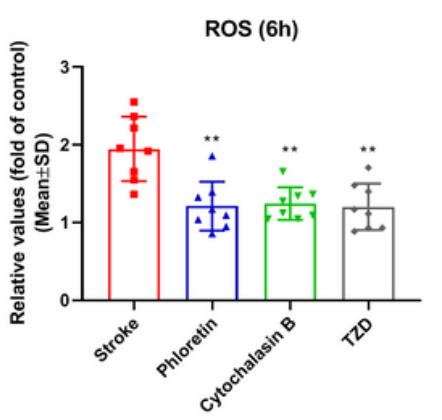

B

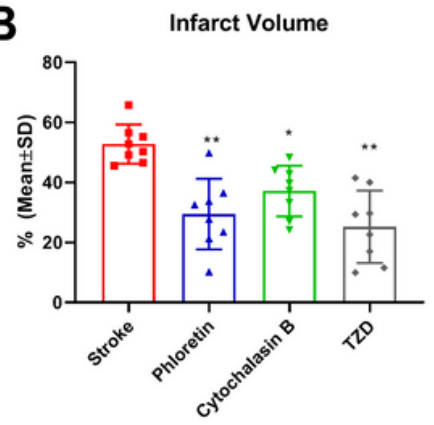

F

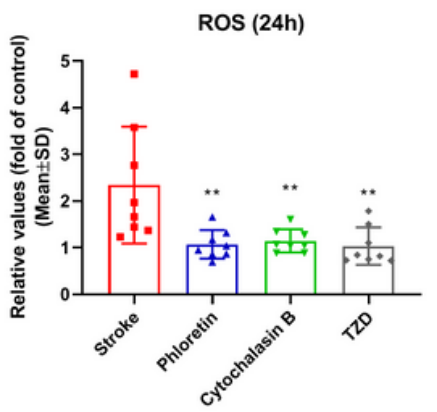

C

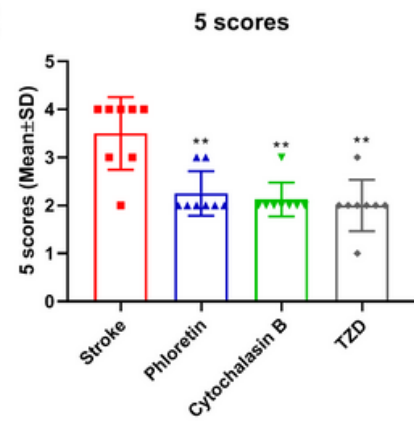

G

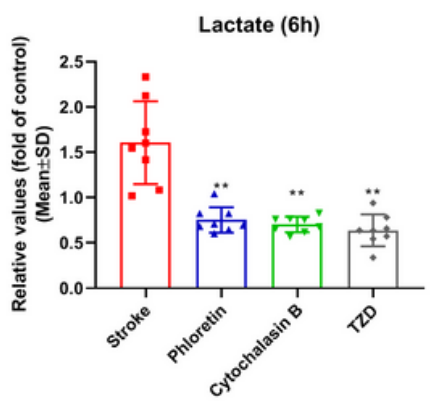

D

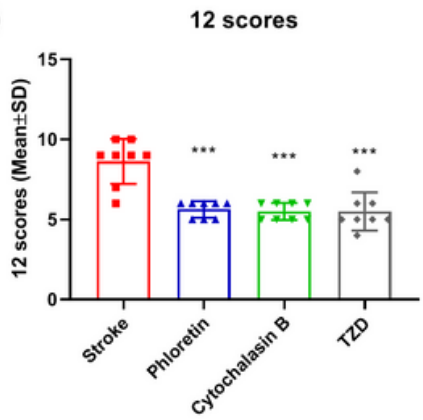

H

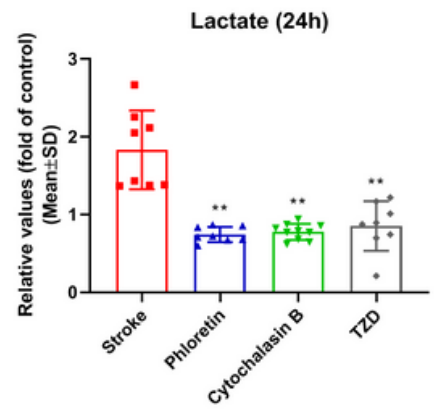

Figure 4

Effect of GLUT-1, GLUT-3 and PCK inhibitor's neuroprotective effects in ischemic stroke rat. (A) Representative brain slices stained with TTC after $2 \mathrm{~h} \mathrm{MCAO}$ and $48 \mathrm{~h}$ of reperfusion. (B) Infarct volumes quantification of TTC sections revealing that both phloretin, cytochalasin B and TZD significantly decreased the infarct volume. Phloretin, cytochalasin B and TZD significantly reduced the neurological deficits at 5 (C) or 12 score (D) scales. ROS levels were significantly decreased by phloretin, cytochalasin B or TZD at $6(E)$ and $24 \mathrm{~h}(\mathrm{~F})$ of reperfusion. Again, phloretin, cytochalasin B or TZD significantly decreased the lactate level at both $6(\mathrm{G})$ and $24 \mathrm{~h}(\mathrm{H})$ after reperfusion. Data are presented as mean $\pm S D, * p<0.05, * * p<0.01$ as compared to stroke group.

A

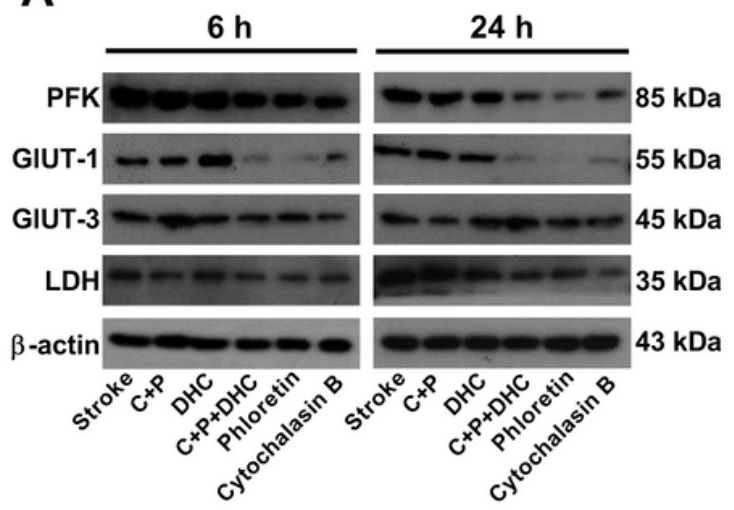

B

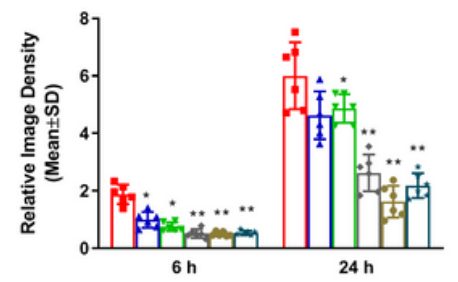

D

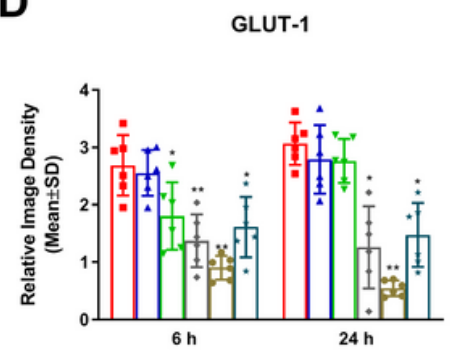

C

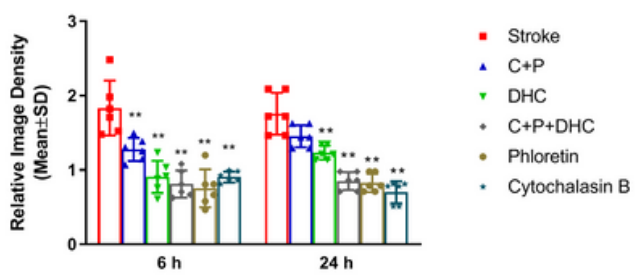

E

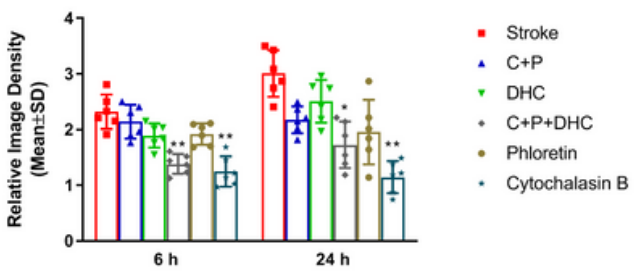


Figure 5

Effect of pharmacological hypothermia on glycolytic enzymes. (A) Representative Western blot bands of glycolytic enzymes. PFK (B, C), LDH (D, E), GLUT-1 (F, G), and GLUT-3 (H, I) levels were significantly reduced by pharmacological hypothermia, phloretin, and cytochalasin B. Data are presented as mean $\pm S D,{ }^{*}<<0.05,{ }^{* *} p<0.01$ as compared to stroke group.

A

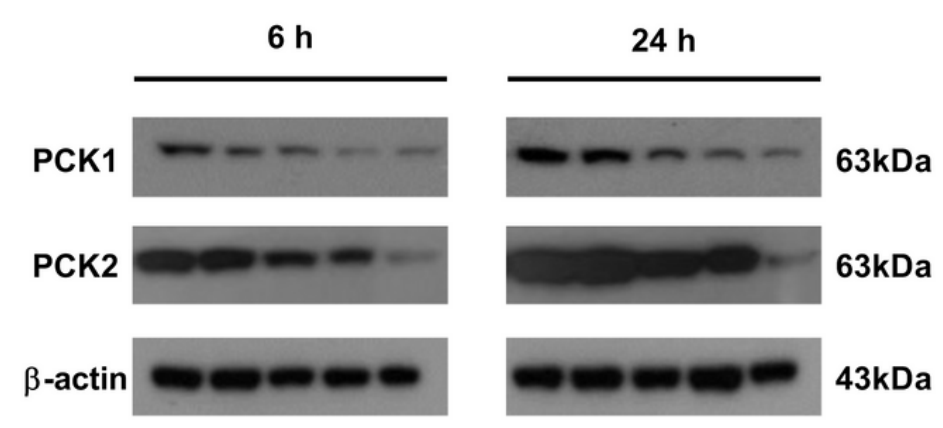

B

PCK 1 (6h)

C PCK $1(24 \mathrm{~h})$
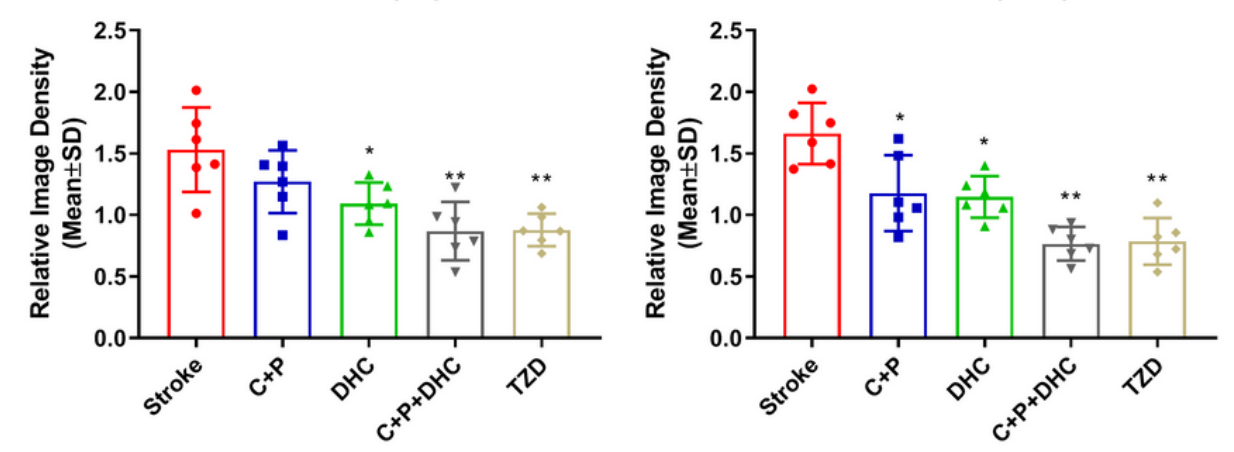

D

PCK 2 (6h)

E

PCK 2 (24h)
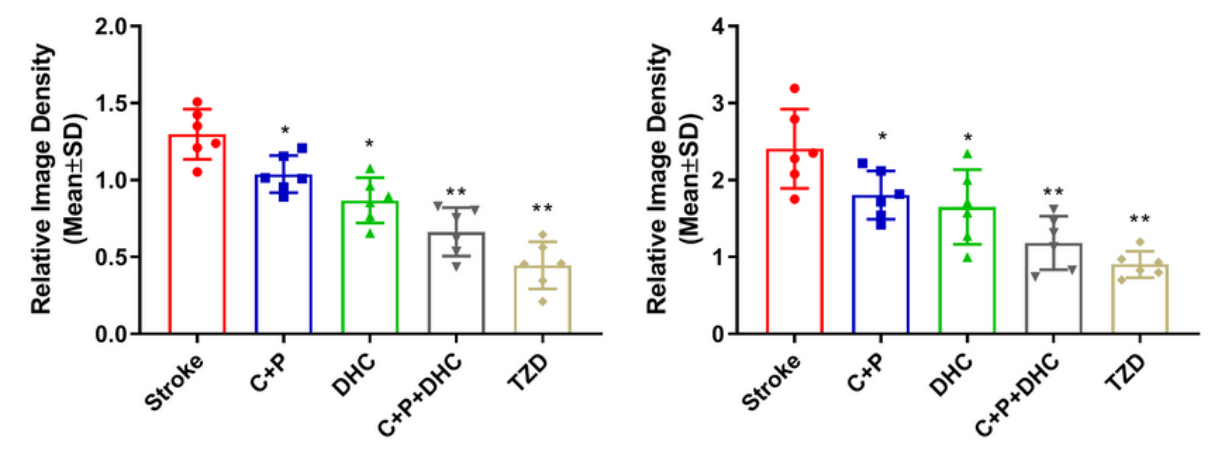

Figure 6

Effect of pharmacological hypothermia on gluconeogenic enzymes. (A) Representative Western blot bands of gluconeogenic enzymes. PCK1 (B, C) and PCK2 (D, E) levels were significantly reduced by pharmacological hypothermia and TZD. Data are presented as mean $\pm S D,{ }^{*} p<0.05$, ${ }^{* *} p<0.01$ as compared to stroke group. 
A

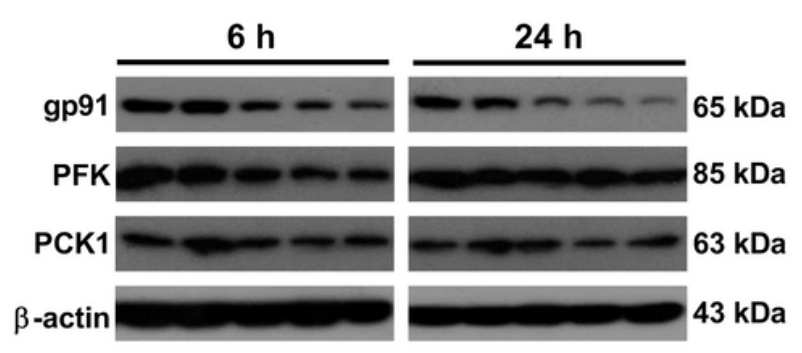

C

PFK

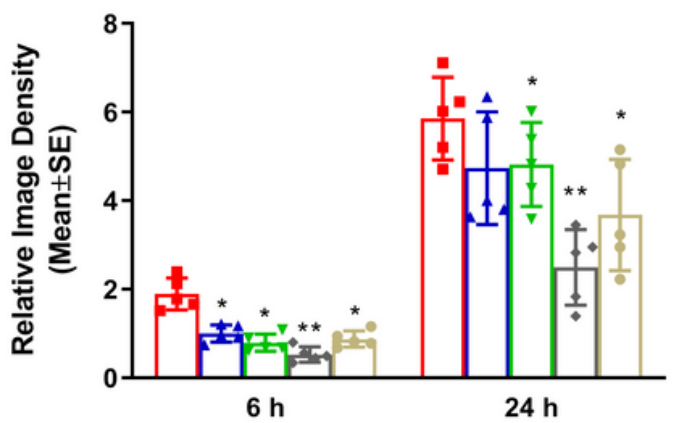

- C+P

$\checkmark$ DHC
B

gp91

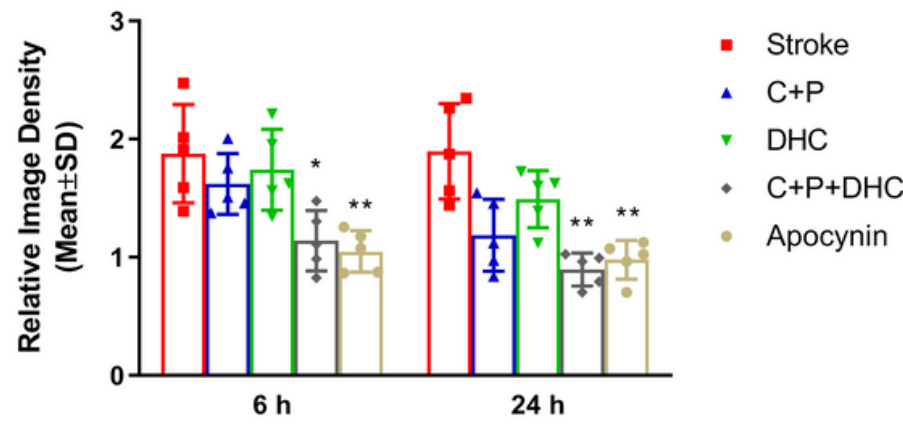

D $\quad$ PCK1

- Stroke

- C+P+DHC

- Apocynin

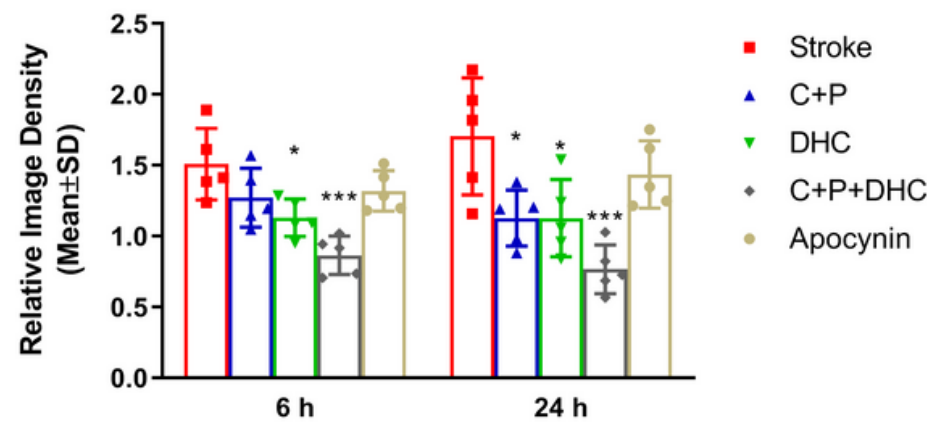

Figure 7

Effect of NOX inhibition on glucose metabolism enzymes. (A) Representative Western blot bands of gp91, PFK and PCK1. gp91 (B, C), PCK1 (D, E) and PFK ( $F, G)$ levels were significantly reduced by pharmacological hypothermia. Apocynin reduced gp91 and PFK protein expression, while didn't reduced PCK1 protein expression. Data are presented as mean $\pm S D,{ }^{*}<<0.05$, ** $p<0.01$ as compared to stroke group. 